\title{
Nutritional Status of Rural Bengali Adolescent Boys of Tripura: Correspondence
}

\author{
Manas Pratim $\operatorname{Roy}^{1}$ (I)
}

Received: 7 September 2015 / Accepted: 11 January 2016/Published online: 11 February 2016

(C) Dr. K C Chaudhuri Foundation 2016

To the Editor: I read with interest the research article on nutritional status published online in Indian Journal of Pediatrics [1]. Although an observational study, the authors deserve appreciation for bringing up data from North East India. However, I have certain queries:

1. What scale was used to measure socio-economic class?

2. WHO recommends use of country specific growth charts for children between 5 and $18 \mathrm{y}$ [2]. So, what is the rationality of comparing new IAP growth charts with WHO standards?

3. "The over diagnosis of undernutrition and under diagnosis of overnutrition may be avoided by using the new IAP growth charts" - from what observation such conclusion was drawn?

\author{
Compliance with Ethical Standards \\ Conflict of Interest None. \\ Source of Funding None.
}

\section{References}

1. Sarkar SR, Sil SK. Nutritional status of rural Bengali adolescent boys of Tripura. Indian J Pediatr. 2015. doi:10.1007/s12098-015-1856-6.

2. Khadilkar V, Yadav S, Agrawal KK, et al; Indian Academy of Pediatrics Growth Charts Committee. Revised IAP growth charts for height, weight and body mass index for 5 - to 18-year-old Indian children. Indian Pediatr. 2015;52: $47-55$.

Manas Pratim Roy

manas_proy@yahoo.co.in

1 Department of Pediatrics, Vardhman Mahavir Medical College and Safdarjung Hospital, New Delhi 110029, India 